\title{
Density-Dependent Growth and Production of Nile Tilapia (Oreochromis niloticus) Fingerlings Relative to Phytoplankton and Periphyton Biomass
}

\author{
W. Jiwyam \\ Fisheries Program, Faculty of Applied Science and Engineering, Khon Kaen University, Nong Khai Campus, \\ Nong Khai Province, Thailand \\ E-mail:wirjiw@kku.ac.th
}

Received: 24.07.2013; Accepted: 03.09.2013

\begin{abstract}
The growth, production and survival of Nile tilapia Oreochromis niloticus, with an average individual weight of $0.2 \mathrm{~g}$ were used to determine the density-dependent growth and production relative to phytoplankton and periphyton biomass in periphyton-based aquaculture. The trial was conducted in $10 \mathrm{~m}^{2}$ concrete tanks for a 56 day period. A 10 $\mathrm{cm}$ layer of soil was placed at the bottom of each tank. To act as substrates for periphyton, bamboo poles with an approximate submerged surface area of 50\% to that of the total tank surface area were vertically posted in the tank bottom. A weekly fertilizer dose of urea and triple superphosphate at a rate of $28 \mathrm{~kg} \mathrm{~N}$ and $7 \mathrm{~kg} \mathrm{P} / \mathrm{ha} /$ week was added. Four stocking densities in triplicate were used: 5, 10, 20, and $40 \mathrm{fish} / \mathrm{m}^{2}$ (50, 100,200 , and 400 fish/tank). The results indicated that the carrying capacity of periphyton-based tanks for Nile tilapia was $293 \mathrm{~g} / \mathrm{m}^{2}$ in a 56-day culture period. The relationships between gross yields of tilapia (y) and periphyton dry matter $(\mathrm{x})$, or chlorophyll $a$ (x) were described as $\mathrm{y}=353.2483-109.1809 \mathrm{x}, R^{2}=0.5646, P=0.005$, y $=125.5916+0.9698 \mathrm{x}, R^{2}=0.5841, P=0.004$. Provision of substrates at $50 \%$ of total tank surface area was sufficient for periphyton production in nutrient-rich aquaculture ponds where grazing rate and fish density in the system are balanced.
\end{abstract}

Key words: Carrying capacity, periphyton-based aquaculture, fish production, primary productivity, dry matter

\section{Introduction}

The assemblage of attached organisms on a submerged surface, including associated non-attached fauna, is referred to as periphyton (van Dam et al., 2002). In aquaculture, they have been used to improve water quality and the production of the culture species (Khatoon et al., 2007). Adding substrates to enhance periphyton growth in fertilized ponds has been shown to increase fish production. A number of studies have shown higher fish production in ponds with substrates for periphyton development than in ponds without substrates (Hem and Avit, 1994; Wahab et al., 1999; Ramesh et al., 1999; Keshavanath et al., 2001; Azim et al., 2001a; Azim et al., 2002a). Growth and the final mean weight of rohu (Labeo rohita), catla (Catla catla) and common carp (Cyprinus carpio) were higher in the substrate treatments than those in the control (Rai et al., 2008). This is due to the fact that filter feeding of planktonic algae is unlikely to fully cover the energy demands of most 
herbivorous carp and tilapia species (Dempster et al., 1995), and they therefore generally require additional food sources such as benthic algae, algal detritus or plant fodder (Dempster et al., 1993; Yakupitiyage, 1993). Periphyton that grows on a substrate in freshwater ponds can serve as one of these additional food sources (Azim and Wahab, 2005). Improving of the conversion of nutrients into harvestable products, through the adoption of periphyton-based production in existing pond systems, is one solution worth exploring (Azim et al., 2003). Although the addition of vertically placed plastic baffles and bamboo poles did not significantly increase net fish yield, differences in attached microorganisms and detrital biomass in tanks with and without fish clearly demonstrated attached microorganisms and detrital biomass was ingested by tilapia (Shrestha and Knud-Hansen, 1994). Additionally, Nile tilapia can grow better grazing on periphyton rather than filtering suspended algae from the water column (Huchette et al., 2000; Azim et al., 2002b), therefore, the periphyton-based system has a very high potential for small-scale Nile tilapia culture, and for producing fingerlings for further grow-out in cages.

Various management practices for pond culture are used for Nile tilapia production in Thailand. Many integrated fish/livestock farms have now turned to produce large Nile tilapia fingerlings (40-50 g) for further stocking in cages. In order to fully utilize the nutrients available in the fertilized fish ponds, applying periphytonbased aquaculture should be an efficient alternative, particularly for Nile tilapia.

Based on a recommended fertilization (Lin et al., 1997), maximum yields of tilapia are attained with nitrogen inputs of 2 to $4 \mathrm{~kg}$
$\mathrm{N} /$ ha/day, phosphorus input levels that should be sufficient to prevent $\mathrm{P}$ limitation, and a $\mathrm{N}: \mathrm{P}$ ration of $4: 1$. However, the current practice of fertilizer and supplemental feed applied systems are inefficient; only 5 to $15 \%$ of nutrients are retained in the fish biomass (Edwards, 1993), most of the remainder being lost to the sediments. Improving the efficiency of nutrient use is of major importance in improving the low input systems of aquaculture technologies (Azim et al., 2004b). Periphyton-based systems have shown higher nutrient utilization efficiency when compared to traditional substrate-free systems (Verdegem et al., 2005; Uddin, 2007), so an optimum fertilization rate for the traditional substrate-free ponds is expected to be sufficient for maximizing fish production in periphyton-based systems. Bamboo was selected as the substrate in this study because of its highquality periphyton production, availability, ease of use, and durability (Ramesh et al., 1999; Keshavanath et al., 2001). For substrate density, previous studies have suggested that adding substrates with a total surface area from 50 to $100 \%$ of the total pond surface area can increase fish production when compared to substrate-free control ponds, although the yields did not vary significantly among three substrate densities (Azim et al., 2004a). Increasing substrate density up to $100 \%$ can increase production costs in periphyton-based systems due to labor needs and availability of substrates. The introduction of substrates equivalent to $50 \%$ of the pond surface area, together with a reduction of $40 \%$ in the feed amount supplied, was tested in tilapia nurseries, early grow-out from 90 to $350 \mathrm{~g}$ (Milstein et al., 2005) and advanced growout from 320 to $520 \mathrm{~g}$ (Milstein et al., 
2009). Furthermore, to encourage large scale adoption by fish farmers and in view of the fact that the major constraint appear to be the availability of suitable substrates, a lesser substrate density requirement for periphyton-based systems would be preferential. So, substrates equivalent to $50 \%$ of the pond surface area was used in the present study.

Previous studies concerning periphyton-based systems did not focus on the contributions between phytoplankton and/or periphyton to growth and production of the fish. Even though both monoculture and polyculture were tested in periphyton based-aquaculture systems (Azim et al., 2001a; Azim et al., 2002a). The previous results indicated that polyculture was better. However, an intensive monoculture of Nile tilapia in low-cost and environmental friendly production system like periphytonbased aquaculture is of interest. In addition, the use of low level stocking densities, 1 or $2 \mathrm{fish} / \mathrm{m}^{2}$ of fingerlings that are traditionally used in substrate-free systems, together with the culture periods of 2 to 5 months may not have been long enough for fish growth to give the total fish biomass that reaches the carrying capacity of the systems, and possibly leading to the wide range of fish yields that were reported from those studies. Moreover, that would not be optimized to determine the role of those natural food sources (phytoplankton and periphyton) for more intensive periphyton-based aquaculture production system. Therefore, the higher stocking densities, 5, 10, 20, and 40 fish $/ \mathrm{m}^{2}$ tested in the present study, was expected to give fish biomass that reached the carrying capacity of the system within a 56-day culture period. In view of the above, the relationship between production of the fish with chlorophyll a production or periphyton can be evaluated. Then the data of the present study will be useful for further development of intensive monoculture of Nile tilapia using periphyton-based system.

Therefore, the purpose of this study was to demonstrate the role of phytoplankton and periphyton in growth and production of Nile tilapia $O$. niloticus fingerlings in periphyton based aquaculture system.

\section{Materials and methods}

The experiment was conducted at Nong Khai Campus, Khon Kean University, Thailand, from August to October 2010. The trial was conducted in twelve concrete tanks with a size of $2.7 \times 3.7 \times 1.2 \mathrm{~m}$ (width $\mathrm{x}$ length $\mathrm{x}$ height, area: $10 \mathrm{~m}^{2}$ ), in which each one had a $10-\mathrm{cm}$ layer of sun-dried bottom soil from an earthen fishpond placed on the bottom. All experimental tanks were filled with well water, and the water depth was maintained at $80 \pm 2 \mathrm{~cm}$ above the soil surface throughout the trial. Bamboo poles (average diameter $5.5 \mathrm{~cm}$, length $150 \mathrm{~cm}$ ) were posted vertically into the tank bottom, at a total density of 35 poles per tank (3.5 poles $/ \mathrm{m}^{2}$ ), giving an additional submerged surface area approximately equal to 50\% of the total tank surface area. All tanks were fertilized with urea and triple super phosphate (TSP) at a rate of $28 \mathrm{~kg} \mathrm{~N}$ and 7 $\mathrm{kg} \mathrm{P} \mathrm{ha/week.} \mathrm{To} \mathrm{achieve} \mathrm{this} \mathrm{fertilization}$ rate, urea and TSP were applied at weekly intervals at $61 \mathrm{~g}$ and $35 \mathrm{~g} / \mathrm{tank}$, respectively. Before the fertilizers were applied, the urea was dissolved with water, and the TSP was soaked in water overnight. After the first fertilization and bamboo pole installation on August 27, the tanks were left for 10 days to allow plankton development in the water column and for periphyton growth on the 
bamboo substrates and then stocked with the fish on September 6. Thereafter, fertilization continued at weekly intervals throughout experimental period.

A population of sex-reversed fingerlings of Nile tilapia $O$. niloticus with an average individual weight of $0.2 \mathrm{~g}$ were stocked in the tanks in triplicates at 5, 10, 20 and $40 \mathrm{fish} / \mathrm{m}^{2}(50,100,200$, and 400 fish/tank), and reared for 56 days without supplementary feed. All fish were weighed at the beginning and at the end of the experiment. Thirty fish from each experimental tank were individually measured for their body weight and total length for condition factor $(\mathrm{K})$ calculation.

Fish from all treatments were harvested after 56 days, and the final mean weight, mean weight gain, specific growth rate, yield and survival rate were calculated as follows: final mean weight $(\mathrm{g})=\mathrm{Tw} / \mathrm{Nf}$, where $\mathrm{Tw}=$ sum of individual weights of harvested fish and $\mathrm{Nf}=$ number of fish; mean weight gain $(\mathrm{g} / \mathrm{fish})=(\mathrm{Wf}-\mathrm{Wi})$, where $\mathrm{Wi}=$ initial mean weight and $\mathrm{Wf}=$ final mean weight; specific growth rate $(\%)$ $=100[(\ln \mathrm{Wf}-\ln \mathrm{Wi})] /$ culture period (days), gross yield $\left(\mathrm{g} / \mathrm{m}^{2}\right)=\mathrm{Tw} / 10 \mathrm{~m}^{2}$; net yield $\left(\mathrm{g} / \mathrm{m}^{2}\right)=(\mathrm{Tw}-\mathrm{Ti}) / 10 \mathrm{~m}^{2}$, where $\mathrm{Ti}=$ sum of individual weights of stocked fish; survival rate $(\%)=100 \mathrm{Nf} / \mathrm{Ni}$, where $\mathrm{Nf}$ and $\mathrm{Ni}=$ final and initial number of fish. At the end of the experiment 30 fish were randomly sampled from each tank, and measured for body weight and total length. Then condition factor $(\mathrm{K})$ was calculated using the formula $\mathrm{K}=$ (fish weight in gram/fish length in $\mathrm{cm}^{3}$ ) $\mathrm{x} 100$.

To evaluate the effect of stocking density on production performance with more precision, the performance index $(\mathrm{PI}=$ mean final weight in $\mathrm{g}-$ mean initial weight in $g$ /days of culture $x$ survival rate in percentage) was calculated (Mohanty, 2004).

A test for homogeneity of variances on final weight of individual fish within each treatment replicate, after grow-out in tanks, was performed by Levene's test using SPSS statistical software.

Water quality in the experimental tanks was monitored weekly between 09:00 and 10:00 h each sampling day at a depth of 25 $\mathrm{cm}$. The tanks were monitored for water temperature (YSI model 52), dissolved oxygen (APHA, 1989), and $\mathrm{pH}$ and conductivity (Hach model sension 5). Composite column water samples were collected fortnightly, and analyzed for chlorophyll $a$ (acetone extraction), total ammonia nitrogen (phenate method), nitrite$\mathrm{N}$ (diazotization), nitrate (cadmium reduction and diazotization), soluble reactive phosphorus (ascorbic acid method), total phosphorous (persulfate digestion and ascorbic acid finish), total dissolved solids, total suspended solids, total alkalinity and total hardness following the Standard Methods for the Examination of Water and Wastewater (APHA, 1989). Total nitrogen was analyzed (Stirling, 1985).

Periphyton samples were collected 10 days after the substrate installation, and continued to be taken at fortnightly intervals thereafter. At each sampling time, one pole from each tank was randomly selected and a $10 \times 10 \mathrm{~cm}$-band of periphyton sample taken at the mid depth level for dry matter (DM) and ash-free dry matter (AFDM) content analyses. Dry matter was determined by drying the samples overnight at $105^{\circ} \mathrm{C}$ to a constant weight, upon which the ash content was determined using a muffle furnace $(4 \mathrm{~h}$ at $540^{\circ} \mathrm{C}$ ). The final weight of the crucible 
along with the remains was taken in order to calculate the amount of ash and ash-free dry matter.

The data on final mean weight, mean weight gain, specific growth rate, survival rate and yield were compared using analysis of variances (ANOVA) and the Tukey-HSD test. The assumptions of normal distribution and homogeneity of the variances were met. The differences were considered statistically significant at an alpha level of 0.05 . Variations of treatment means are presented in "mean \pm standard deviation".

\section{Results}

Table 1 shows the mean values of growth and yield parameters of the experimental fish. The mean initial weights of the experimental fish were not significantly different $(P>0.05)$; however the final weights were significantly different $(P<$ 0.05 ). Levene's test is used to assess the equality of variances on final individual weight of the fish in different treatments. The resulting p-values of the Levene's test for each treatment, 50, 100, 200 or 400 fish/tank were $0.083,0.083,0.217$ or 0.081 respectively, which indicated homogeneity of variances in each treatment. Final mean weight of the fish at the lowest stocking density was significantly higher than those of the higher densities from 100 to 400 fish /tank. While no significant difference in final mean weight was found at stocking densities from 200 to 400 fish/tank, mean weight gain, specific growth rate, and gross yield of the fish were significantly different among the stocking densities $(P<0.05)$. Specific growth rates from all stocking densities ranged from 6.56 to $9.24 \%$ /day. Survival rate of the fish from all treatments was higher than $95 \%$, and were not significantly different $(P>0.05)$. Gross yields were not significantly different among the stocking densities of 50, 100 and 200 fish/tank $(P>0.05)$. Gross yields between stocking density 100 and 200 fish/tank was not significantly different, while the final mean weight of the 100 fish/tank density was almost double (1.96 times) that of the 200 fish/tank density. Condition factors (K) was highest at stocking density of 400 fish/tank, and was greater than those of stocking densities 50 and $100 \mathrm{fish} / \operatorname{tank}(P<0.05)$. However there was no significant difference among stocking densities of 50 and 100 fish/tank. Performance indices were significantly different among different stocking densities $(P<0.05)$, and reduced drastically at stocking densities of 200 to 400 fish /tank.

Table 2 shows the mean values of periphyton biomass measured from different fish stocking densities throughout the experimental period. Mean periphyton biomass in DM and AFDM in the high stocking densities, 100, 200 and 400 fish/tank were significantly different from the lowest density, 50 fish/tank, $(P<0.05)$ during the experimental period. The value of periphyton biomass in the DM in the study was $1.14 \pm 0.57 \mathrm{mg} / \mathrm{cm}^{2}$, and ranged between 0.41 and $3.17 \mathrm{mg} / \mathrm{cm}^{2}$. The value of the periphyton biomass in AFDM was $0.53 \pm 0.38 \mathrm{mg} / \mathrm{cm}^{2}$, and ranged between 0.15 and $2.01 \mathrm{mg} / \mathrm{cm}^{2}$. The average ash content was $53 \%$. The mean values $(\mathrm{N}=60)$ for periphyton biomass in AFDW was 0.53 $\pm 0.38 \mathrm{mg} / \mathrm{cm}^{2}$. The overall ranging values $(\mathrm{N}=60)$ for periphyton $\mathrm{DM}$ and AFDW were 0.41 to $3.17 \mathrm{mg} / \mathrm{cm}^{2}$ and 0.15 to 2.01 $\mathrm{mg} / \mathrm{cm}^{2}$, respectively. There was a significant negative relationship between gross yields and the DM of periphyton $(P<$ 0.05; Fig. 1). 
W. Jiwyam / Our Nature (2013), 11(2): 105-115

Table 1. Growth and survival of fingerling Nile tilapia stocked in bottom-soil concrete tanks at different stocking densities with provision of bamboo substrates, and loaded with chemical fertilizers for a 56-day culture period.

\begin{tabular}{|c|c|c|c|c|}
\hline \multirow[t]{2}{*}{ Parameters } & \multicolumn{4}{|c|}{ Stocking density (fish/tank) } \\
\hline & $\mathbf{5 0}$ & 100 & 200 & 400 \\
\hline Initial mean weight (g/fish) & $0.2 \pm 0.0$ & $0.2 \pm 0.0$ & $0.2 \pm 0.0$ & $0.2 \pm 0.0$ \\
\hline Final mean weight (g/fish) & $35.1 \pm 6.1^{\mathrm{c}}$ & $24.0 \pm 1.7^{\mathrm{b}}$ & $11.2 \pm 1.1^{\mathrm{a}}$ & $7.7 \pm 1.2^{\mathrm{a}}$ \\
\hline Mean weight gain (g/fish) & $34.9 \pm 6.1^{\mathrm{c}}$ & $23.8 \pm 1.7^{\mathrm{b}}$ & $11.0 \pm 1.1^{\mathrm{a}}$ & $7.5 \pm 1.2^{\mathrm{a}}$ \\
\hline Specific growth rate (\%/day) & $9.2 \pm 0.3^{\mathrm{c}}$ & $8.5 \pm 0.2^{\mathrm{b}}$ & $7.2 \pm 0.2^{\mathrm{a}}$ & $6.6 \pm 0.3^{\mathrm{a}}$ \\
\hline Survival (\%) & $98.0 \pm 0.0$ & $97.0 \pm 2.0$ & $97.2 \pm 2.1$ & $95.7 \pm 3.3$ \\
\hline Gross yield $\left(\mathrm{g} / \mathrm{m}^{2}\right)$ & $171.9 \pm 30.1^{\mathrm{a}}$ & $232.2 \pm 12.6^{\mathrm{ab}}$ & $217.6 \pm 18.3^{\mathrm{a}}$ & $293.4 \pm 37.0^{\mathrm{b}}$ \\
\hline Net yield $\left(\mathrm{g} / \mathrm{m}^{2}\right)$ & $170.9 \pm 30.1^{\mathrm{a}}$ & $230.2 \pm 12.6^{\mathrm{ab}}$ & $213.5 \pm 18.4^{\mathrm{a}}$ & $285.7 \pm 37.5^{\mathrm{b}}$ \\
\hline Condition factor $(\mathrm{K})$ & $1.66 \pm 0.11^{\mathrm{a}}$ & $1.68 \pm 0.15^{\mathrm{a}}$ & $1.72 \pm 0.24^{\mathrm{ab}}$ & $1.85 \pm 0.66^{\mathrm{b}}$ \\
\hline Performance index (PI) & $61.0 \pm 10.8^{c}$ & $41.1 \pm 2.3^{\mathrm{b}}$ & $19.1 \pm 1.6^{\mathrm{a}}$ & $12.8 \pm 1.7^{\mathrm{a}}$ \\
\hline
\end{tabular}

The means in a row with different superscripts are significantly different $(P<0.05$, Tukey-HSD test).

Table 2. One-way ANOVA of periphyton biomass in dry matter and ash-free dry matter, obtained from substrates in different stocking densities during the experiment. All are means \pm standard deviation.

\begin{tabular}{|c|c|c|c|c|c|}
\hline \multirow{2}{*}{$\begin{array}{l}\text { Periphyton } \\
\text { biomass }\end{array}$} & \multicolumn{4}{|c|}{ Stocking (fish/tank) } & \multirow{2}{*}{$\begin{array}{c}\text { Overall } \\
\text { Mean } \pm \text { SD (range) }\end{array}$} \\
\hline & 50 & 100 & 200 & 400 & \\
\hline$\overline{\mathrm{DM}}\left(\mathrm{mg} / \mathrm{cm}^{2}\right)$ & $1.64 \pm 0.61^{b}$ & $1.05 \pm 0.37^{\mathrm{a}}$ & $1.01 \pm 0.52^{\mathrm{a}}$ & $0.86 \pm 0.45^{\mathrm{a}}$ & $1.14 \pm 0.57(0.41-3.17)$ \\
\hline $\operatorname{Ash}\left(\mathrm{mg} / \mathrm{cm}^{2}\right)$ & $0.76 \pm 0.32^{\mathrm{b}}$ & $0.61 \pm 0.20^{\mathrm{ab}}$ & $0.57 \pm 0.25^{\mathrm{ab}}$ & $0.51 \pm 0.18^{\mathrm{b}}$ & $0.61 \pm 0.25(0.07-1.18)$ \\
\hline $\operatorname{AFDM}\left(\mathrm{mg} / \mathrm{cm}^{2}\right)$ & $0.88 \pm 0.43^{\mathrm{b}}$ & $0.44 \pm 0.24^{\mathrm{a}}$ & $0.44 \pm 0.31^{\mathrm{a}}$ & $0.36 \pm 0.31^{\mathrm{a}}$ & $0.53 \pm 0.38(0.15-2.01)$ \\
\hline
\end{tabular}

The means in a row with different superscripts are significantly different $(P<0.05$, Tukey-HSD test).

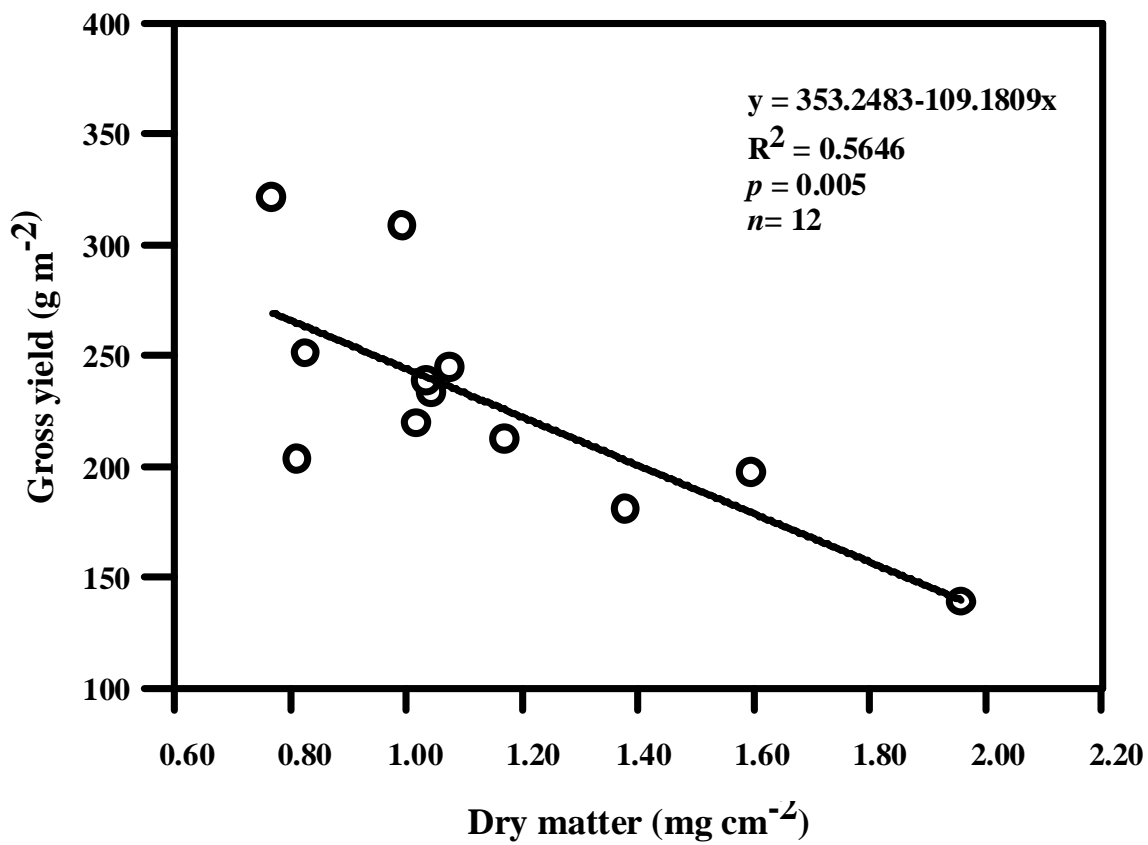

Figure 1. Linear relationship between gross yield of Nile tilapia and DM from a 56-day culture period of Nile tilapia in periphyton-based aquaculture tanks. 
W. Jiwyam / Our Nature (2013), 11(2): 105-115

Table 3. Water quality parameters measured throughout the experimental period over a 56-day culture period of Nile tilapia in periphyton-based aquaculture tanks. All are mean \pm standard deviation.

\begin{tabular}{lcccc}
\hline \multirow{2}{*}{ Parameters } & \multicolumn{4}{c}{ Stocking density (fish/tank) } \\
\cline { 2 - 5 } & $\mathbf{5 0}$ & $\mathbf{1 0 0}$ & $\mathbf{2 0 0}$ & $\mathbf{4 0 0}$ \\
\hline pH & $9.11 \pm 0.75$ & $9.04 \pm 0.69$ & $9.03 \pm 0.82$ & $9.21 \pm 0.80$ \\
Conductivity $(\mu \mathrm{S} / \mathrm{cm})$ & $228.15 \pm 9.17$ & $220.97 \pm 10.61$ & $235.62 \pm 10.87$ & $200.59 \pm 8.17$ \\
Temp $\left({ }^{\circ} \mathrm{C}\right)$ & $28.8 \pm 1.49$ & $28.8 \pm 1.45$ & $28.8 \pm 1.53$ & $28.8 \pm 1.51$ \\
Dissolved oxygen $(\mathrm{mg} / \mathrm{l})$ & $6.90 \pm 3.18$ & $7.63 \pm 3.16$ & $6.89 \pm 2.49$ & $6.92 \pm 2.74$ \\
Total ammonia $(\mathrm{mg} / \mathrm{l})$ & $0.19 \pm 0.04$ & $0.17 \pm 0.04$ & $0.17 \pm 0.04$ & $0.18 \pm 0.03$ \\
Nitrite $(\mathrm{mg} / \mathrm{l})$ & $0.24 \pm 0.18$ & $0.25 \pm 0.13$ & $0.23 \pm 0.12$ & $0.22 \pm 0.18$ \\
Nitrate $(\mathrm{mg} / \mathrm{l})$ & $1.40 \pm 0.75$ & $1.68 \pm 0.95$ & $1.45 \pm 1.09$ & $1.43 \pm 1.01$ \\
Total nitrogen $(\mathrm{mg} / \mathrm{l})$ & $2.07 \pm 0.82$ & $2.17 \pm 0.96$ & $2.01 \pm 1.10$ & $2.03 \pm 1.13$ \\
Soluble reactive phosphorus $(\mathrm{mg} / \mathrm{l})$ & $0.64 \pm 0.45$ & $0.54 \pm 0.28$ & $0.36 \pm 0.26$ & $0.43 \pm 0.25$ \\
Total phosphorus (mg/l) & $1.01 \pm 0.60$ & $0.89 \pm 0.44$ & $0.67 \pm 0.35$ & $0.758 \pm 0.36$ \\
Chlorophyll $a(\mu \mathrm{g} / \mathrm{l})$ & $70.21 \pm 52.49^{\mathrm{a}}$ & $96.23 \pm 67.59^{\mathrm{ab}}$ & $112.27 \pm 62.64^{\mathrm{ab}}$ & $146.84 \pm 80.01^{\mathrm{b}}$ \\
Total alkalinity $(\mathrm{mg} / \mathrm{l})$ & $154.13 \pm 32.51$ & $157.66 \pm 33.44$ & $161.33 \pm 36.31$ & $142.71 \pm 29.83$ \\
Total hardness $(\mathrm{mg} / \mathrm{l})$ & $90.30 \pm 24.28$ & $94.10 \pm 23.43$ & $95.37 \pm 25.75$ & $79.03 \pm 17.43$ \\
Total dissolved solid $(\mathrm{mg} / \mathrm{l})$ & $137.87 \pm 30.40^{\mathrm{b}}$ & $142.42 \pm 41.47^{\mathrm{b}}$ & $132.12 \pm 26.63^{\mathrm{ab}}$ & $112.81 \pm 23.75^{\mathrm{a}}$ \\
Total suspended solid $(\mathrm{mg} / \mathrm{l})$ & $280.40 \pm 85.67$ & $274.80 \pm 83.68$ & $268.67 \pm 67.40$ & $247.07 \pm 61.76$ \\
Secchi disc visibility $(\mathrm{cm})$ & $28.67 \pm 10.72$ & $31.25 \pm 9.26$ & $32.65 \pm 8.53$ & $30.21 \pm 5.63$ \\
\hline The means in a row with different superscripts are significantly different $(P<0.05$, Tukey-HSD test).
\end{tabular}

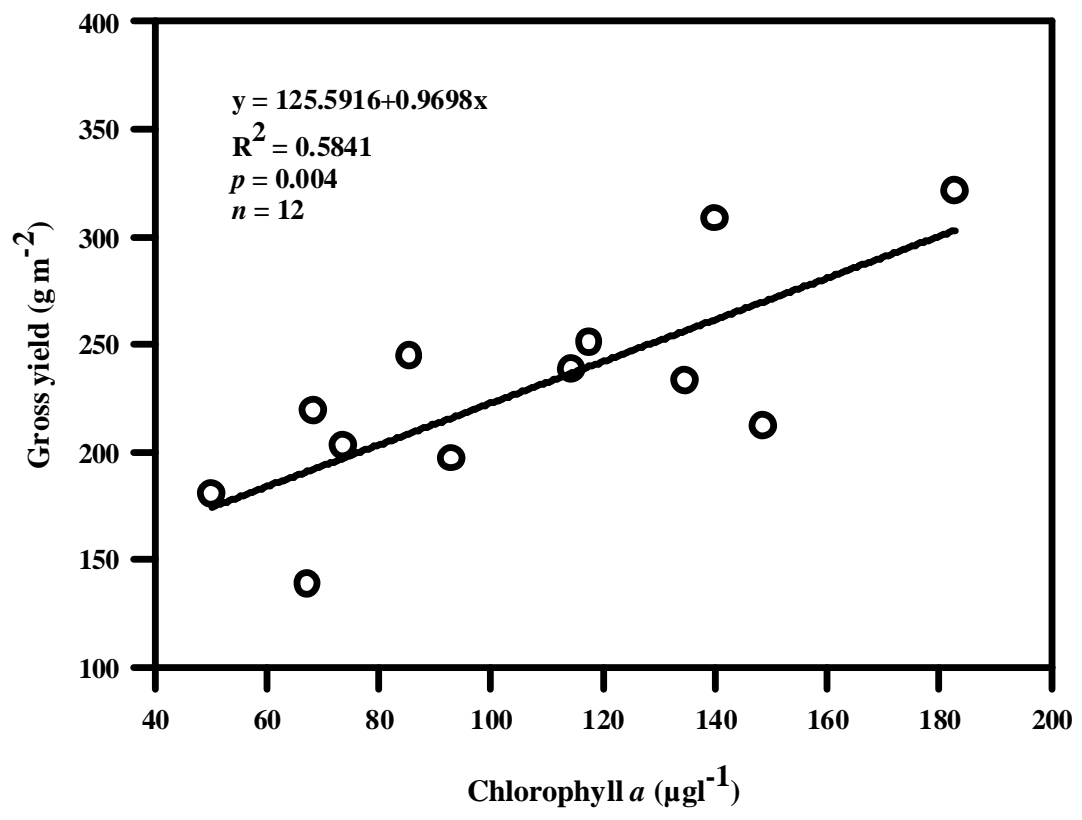

Figure 2. Linear relationship between gross yield of Nile tilapia and chlorophyll $a$ concentration from a 56-day culture period of Nile tilapia in periphyton-based aquaculture tanks. 
Table 3 shows the mean values of the water quality monitored throughout the experimental period. Most of water quality parameters were not significantly different among the stocking densities $(P>0.05)$, except chlorophyll a concentrations and total dissolved solids $(P<0.05)$. The Secchi disc depth in all stocking densities was rather constant at approximately $30 \mathrm{~cm}$ throughout the experimental period. Averaged dissolved oxygen concentration from all fish stocking densities during the culture period was $7.10 \mathrm{mg} / \mathrm{l}$. There was a significant positive relationship between chlorophyll $a$ concentration and gross yield of Nile tilapia $(P<0.05 ;$ Fig. 2). Chlorophyll $a$ seemed to be increased as periphyton biomass (dry weight basis) became less, although there was no significant regression relationship $(\mathrm{p}>0.05)$.

\section{Discussion}

The survival rate of the fish from all stocking densities was higher than $95 \%$. The high growth rate of 6.6 to $9.2 \%$ achieved in the present study was in agreement with the previous studies. For example, the highest specific growth rate of Nile tilapia fry reared in a net enclosure suspended in a fertilized pond at $150 \mathrm{fish} / \mathrm{m}^{2}$ with supplemental feeding was $7.6 \%$ (Little et al., 2003).

In the present study, the highest gross yield over the 56 day period was $293.4 \mathrm{~g} / \mathrm{m}^{2}$ (giving an estimated 17.6 tons/ha/year). This value gave an extrapolated yield of approximately $52.4 \mathrm{~kg} / \mathrm{ha} /$ day. With regards to periphyton-based systems, reported yields include $5.94 \mathrm{~kg} / \mathrm{ha} /$ day of kalbaush Labeo calbasu (Wahab et al., 1999); 15.83 $\mathrm{kg} / \mathrm{ha} / \mathrm{day}$ of rohu Labeo rohita (Azim et al., 2001a); $8.37 \mathrm{~kg} / \mathrm{ha} /$ day of rohu and catla Catla catla (Azim et al., 2002a). In systems where fish stocking is not limited, production level can be largely extended as reported from the acadja systems (4 to 20 tonnes/ha/year) (Welcomme, 1972). The gross yield received in the present study was higher than those reports suggesting that the carrying capacity of those systems may not have been reached. The main factors affecting those results may be from less initial stocking densities.

There was no significant difference in the levels of dissolved oxygen among the different treatments, although the biomass of the fish at the highest stocking density was about 1.7 times higher than that of the lowest stocking density. Furthermore, average dissolved oxygen concentrations in all stocking densities were high with values ranging between 6.0 and $7.6 \mathrm{mg} / \mathrm{l}$ during the culture period. The results, as well as observations, suggest that water turbulence induced by the grazing activity of the fish may increase dissolved oxygen diffusion, particularly at the uppermost area of the water column.

High ash content of periphyton in the present study (53\%) may also have been linked to the concentration of suspended silt in the water column. However, this value fell within the range that was reported in a previous study (Azim et al., 2001b). The study showed a significant difference in periphyton biomass between the lowest stocking density (50 fish/tank) and the high stocking densities (100, 200 and 400 fish/tank). The average values for periphyton biomass in the AFDW reported in an earlier experiment with bamboo substrates and supplemental feeding, and fish were stocked at $1 \mathrm{fish} / \mathrm{m}^{2}$ was 0.12 $\mathrm{mg} / \mathrm{cm}^{2} \quad(50 \%$ substrate density without feeding) to $0.10 \mathrm{mg} / \mathrm{cm}^{2}$ (100\% substrate density with feeding) (Keshavanath et al., 2004). These values are lower when 
compared to the average periphyton AFDM during the culture period of the present study, which indicates that a substrate density of $50 \%$ of total pond surface area is sufficient for periphyton production in a system. Due to the fact that productivity per unit substrate area was highest at intermediate grazing levels (Lamberti and Moore, 1984), and the grazed periphyton communities were younger, healthier and more productive (Huchette et al., 2000). Therefore, it follows that a lower substrate density of $50 \%$ of total pond surface area can be recommended due to the reduced costs incurred at this level.

No significant difference in periphyton biomass was observed among the high stocking densities $(100,200$ and 400 fish/tank). Because of the high grazing pressure, a fixed periphyton biomass was established. While the development of the standing biomass of periphyton per unit substrate is usually known to principally depend upon nutrient and light conditions, the regulation of fish grazing activity appears here to be a good means by which the rate of food production can be maximized under a given set of environmental conditions (Huchette et al., 2000). This also implies that the carrying capacity of the pond might have been reached.

Although no significant difference was found in periphyton biomass among the higher stocking densities from 100 to 400 fish/tank, periphyton biomass at 100 fish/tank density seems to be higher than those of 200 or 400 fish/tank. This finding suggests that the availability of periphyton as a food source was not limited at this density. Furthermore, phytoplankton, which is indicated by average chlorophyll $a$ concentration, was also available through the experimental period, therefore even the fish at the higher stocking density of 200 fish/tank were not in starvation condition. Condition factors of the fish from all stocking densities ranged from 1.66 to 1.85 , with an average 1.73 , which are within the range has been reported (de Graaf, 2004). The condition factor index of the fish did not clearly show the effect of food availability for the 50 to 200 fish $\operatorname{tank}^{-1}$ densities; condition factors among the low stocking density (50 fish/tank) and the high stocking densities, 100 or 200 fish/tank, was not significantly different. But it was noted that the mean condition factor of the fish in the highest stocking density (400 fish/tank) differed significantly from those lower stocking densities. Similarly, performance index (PI) of the fish was drastically reduced at the stocking densities from 200 to $400 \mathrm{fish} / \mathrm{tank}$. The reduction of PI from 50 to 100 fish/tank and from 100 to 200 fish/tank were higher than from 200 to 400 fish/tank. These may have been linked to high feeding competition among the fish due to less availability of plankton and/or periphyton at the highest stocking density.

The contributions of periphyton to fish yields were observed and the coefficient of determinations between gross yields of tilapia (y) and DM (x), or chlorophyll $a$ (x) were described as $\mathrm{y}=353.2483-109.1809 \mathrm{x}$, $R^{2}=0.5646, P=0.005, \mathrm{y}=125.5916+$ $0.9698 \mathrm{x}, R^{2}=0.5841, P=0.004$. These coefficients implied the contribution of phytoplankton to fish yield was approximately $58 \%$. While in substrate-free tilapia ponds, a coefficient between net fish yield and chlorophyll $a$ of $R^{2}=0.89$ was noted by Almazan and Boyd (1978). The enhancement of fish production from 41 to $75 \%$ by periphyton alone was reported by Keshavanath et al. (2002). 
In conclusion, as substrates were increased the contribution of phytoplankton to fish production was decreased. This indicated that the periphyton- based aquaculture system was more preferable for the grazer feeder fish rather than the filter feeder. Consequently, to optimize the utilization of the available natural food in the system, polyculture with appropriate combination of grazer feeder fish and filter feeder fish need to be carefully determined.

\section{Acknowledgements}

This research was supported financially by Nong Khai Campus, Khon Kaen University. The Research and Development Center for Aquatic Animals Technology, Nong Khai Campus, Khon Kaen University is acknowledged for the provision of materials, equipments and research facilities.

\section{References}

Almazan, G. and C.E. Boyd 1978. Plankton production and tilapia yield in ponds. Aquaculture 15(1): 75-77.

APHA (American Public Health Association), American Water Works Association and Water Pollution Control Federation, 1989. Standard Methods for the Examination of Water and Wastewater, $17^{\text {th }}$ edn. American Public Health Association, Washington, DC.

Azim, M.E, M.C.J. Verdgem, M.M. Rahman, M.A. Wahab, A.A. van Dam and M.C.M. Beveridge 2002a. Evaluation of polyculture of Indian major carps in periphyton-based ponds. Aquaculture 213: 131-149.

Azim, M.E. and M.A. Wahab, 2005. Periphytonbased pond polyculture. In Periphyton: Ecology, Exploitation and Management (Eds. M.E. Azim, M.C.J. Verdegem, A.A. van Dam and M.C.M. Beveridge), CABI Publishing, UK. pp. 207-222.

Azim, M.E., A. Milstein, M.A. Wahab, M.C.J. Verdegem, 2003. Periphyton-water quality relationships in fertilized fishponds with artificial substrates. Aquaculture 228: 169-187.

Azim, M.E., M.A. Wahab, A.A. van Dam, M.C.M. Beveridge and M.C.J. Verdegem 2001a. The potential of periphyton-based culture of two Indian major carps, rohu Labeo rohita and gonia Labeo gonius (Linnaeus). Aquac. Res. 32: 209216.

Azim, M.E., M.A. Wahab, A.A. van Dam, M.C.M. Beveridge, A. Milstein and M.C.J. Verdegem 2001b.Optimization of fertilization rate for maximizing periphyton production on artificial substrates and the implications for periphytonbased aquaculture. Aquac. Res. 32: 749-760.

Azim, M.E., M.A. Wahab, M.C.J. Verdegem, A.A. van Dam, J.M. van Rooij and M.C.M. Beveridge $2002 \mathrm{~b}$. The effects of artificial substrates on freshwater pond productivity and water quality and the implications for periphyton-based aquaculture. Aquat. Living Resour. 15: 231-241.

Azim, M.E., M.A. Wahab, P.K. Biswas, T. Asaeda, T. Fujino and M.C.J. Verdegem 2004a. The effect of periphyton substrate density on production in freshwater polyculture ponds. Aquaculture 232: 441-453.

Azim, M.E., M.M. Rahaman, M.A. Wahab, T. Asaeda, D.C. Little and M.C.J. Verdegem 2004b. Periphyton-based pond polyculture system: a bioeconomic comparison of on-farm and onstation trials. Aquaculture 242: 381-396.

de Graaf, G.J. 2004. Optimisation of the Pond Rearing of Nile Tilapia (Oreochromis niloticus L.). The Impact of Stunting Process and Recruitment Control. PhD Thesis. Wageningen University.

Dempster, P.W., D.J. Baird and M.C.M. Beveridge 1995. Can fish survive by filter feeding on microparticles? Energy balance in tilapia grazing on algal suspensions. J. Fish Biol. 47: 7-17.

Dempster, P.W., M.C.M. Beveridge and D.J. Baird 1993. Herbivory in the tilapia Oreochromis niloticus: A comparison of feeding rates of phytoplankton and periphyton. J. Fish Biol. 43: 385-392.

Edwards, P. 1993. Environmental issues in integrated agriculture-aquaculture and waste water fed fish culture systems. In Environment and Aquaculture in Developing Countries (Eds. R.S.V. Pullin, H. Rosenthal and J.L. Maclean), ICLARM Conf Proc, vol. 31. pp. 139-170.

Hem, S. and J.L.B. Avit 1994. First results on 'acadjas enclos'as an extensive aquaculture system (West Africa). Bull. Mar. Sci. 55: 10381049.

Huchette, S.M.H., M.C.M. Beveridge, D.J. Baird and M. Ireland 2000. The impacts of grazing by tilapias (Oreochromis niloticus L.) on periphyton 
communities growing on artificial substrate in cages. Aquaculture 186: 45-60.

Keshavanath, P., B. Gangadhar, T.J. Ramesh, A.A. van Dam and M.C.M. Beveridge 2004. Effects of bamboo substrate and supplemental feeding on growth and production of hybrid red tilapia fingerlings (Oreochromis mossambicus $\mathrm{x}$ Oreochromis niloticus). Aquaculture 235: 303314.

Keshavanath, P., B. Gangadhar, T.J. Ramesh, A.A. van Dam, M.C.M. Beveridge and M.C.J. Verdegem 2002. The effect of periphyton and supplemental feeding on the production of the indigenous carps Tor khudree and Labeo fimbriatus. Aquaculture 213: 207-218.

Keshavanath, P., B. Ganghadar, T.J. Ramesh, J.M. Van Rooij, M.C.M. Beveridge, D.J. Baird, M.C.J. Verdegem and A.A. van Dam 2001. The potential of artificial reefs to enhance production of herbivorous fish in Indian freshwater pondspreliminary trials. Aquac. Res. 32: 189-197.

Khatoon, H., F. Yusoff, S. Banerjee, M. Shariff and J.S. Bujang 2007. Formation of periphyton biofilm and subsequent biofouling on different substrates in nutrient enriched brackishwater shrimp ponds. Aquaculture 273: 470-477.

Lamberti, G.A. and J.W. Moore, 1984. Aquatic insects as primary consumers. In The Ecology of Aquatic Insects (Eds. V.H. Resh and D.M. Rosenberg), Praeger Scientific, New York. pp. 164-195.

Lin, C.K., D.R. Teichert-Coddington, B.W. Green and K.L. Veverica 1997. Fertilization regimes. In Dynamics of Pond Aquaculture (Eds. H.S. Egna and C.E. Boyd), CRC Press, LLC. pp 73-107.

Little, D.C., R.C. Bhujel and T.A. Pham 2003. Advanced nursing of mixed-sex and mono-sex tilapia (Oreochromis niloticus) fry, and its impact on subsequent growth in fertilized ponds. Aquaculture 221: 265-276.

Milstein, A., D. Joseph, Y. Peretz and S. Harpaz 2005. Evaluation of organic tilapia culture in periphyton-based ponds. Isr. J. Aquac. Bamid. 57: 143-155.

Milstein, A., Y. Peretz and S. Harpaz 2009. Culture of organic tilapia to market size in periphyton-based ponds with reduced feed inputs. Aquac. Res. 40: 55-59.

Mohanty, R.K. 2004. Density-dependent growth performance of Indian major carps in rainwater reservoirs. J. Appl. Ichthyol. 20: 123-127.

Rai, S., Y. Yi, M.A. Wahab, A.N. Bart and J.S. Diana 2008. Comparison of rice straw and bamboo stick substrates in periphyton-based carp polyculture systems. Aquac. Res. 39(5): 464-473.

Ramesh, M.R., K.M. Shankar, C.V. Mohan and T.J. Varghese 1999. Comparison of three plant substrates for enhancing carp growth through bacterial biofilm. Aquac. Eng. 19: 119-131.

Shrestha, M.K. and C.F. Knud-Hansen 1994. Increasing attached microorganism biomass as a management strategy for Nile tilapia (Oreochromis niloticus) production. Aquac. Eng. 13(2): 101-108.

Stirling, H.P. 1985. Chemical and Biological Method of Water Analysis for Aquaculturists. Institute of Aquaculture, University of Stirling, Scotland.

Uddin, M.S. 2007. Mixed culture of tilapia (Oreochromis niloticus) and freshwater prawn (Macrobrachium rosenbergii) in periphytonbased ponds. $\mathrm{Ph} \mathrm{D}$ Thesis, Wageningen University, The Netherlands.

van Dam, A.A., M.C.M. Beveridge, M.E. Azim and M.C.J. Verdegem 2002. The potential of fish production based on periphyton. Rev. Fish Biol. Fish. 12(1): 1-31.

Verdegem, M.C.J., E.H. Eding, V. Sereti, R.N. Munubi, R.A. Satacruz-Reyes and A.A. van Dam 2005. Similarities between microbial and perphytic biofilms in aquaculture systems. In Periphyton: Ecology, Exploitation and Management (Eds. M.E. Azim, M.C.J. Verdegem, A.A. van Dam and M.C.M. Beveridge), CABI Publishing, Wallingford, UK. pp. 191-205.

Wahab, M.A., M.E. Azim, M.H. Ali, M.C.M. Beveridge and S. Khan 1999. The potential of periphyton- based culture of the native major carp kalbbaush, Labeo calbasu (Hamilton). Aquac Res. 30: 409-419.

Welcomme, R.L. 1972. An evaluation of the acadja method of fishing as practiced in the coastal lagoons of Dahomey (West Africa). J. Fish Biol. 4: 39-55.

Yakupitiyage, A. 1993. Constraints to the use of plant fodder as fish feed in tropical small scale tilapia culture systems: an overview. In Fish nutrition in practice (Eds. S.J. Kaushik and P. Luquet), Institut Nationale de la Recherche Agronomique, Les Colloques, no 61, Paris. pp 681-689. 